\title{
Coronary artery aneurism - is a stent enough?
}

\section{Sandra Makarović*, Marin Vučković, ZZorin Makarović, Damir Kirner}

University Hospital Centre Osijek, Osijek, Croatia
RECEIVED:

February 19, 2020

ACCEPTED:

February 22, 2020

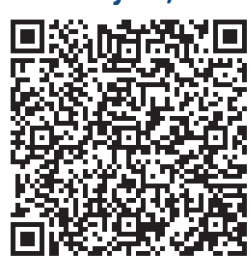

KEYWORDS: coronary artery aneurism, management, covered stent.

CITATION: Cardiol Croat. 2020;15(3-4):45. | https://doi.org/10.15836/ccar2020.45

*ADDRESS FOR CORRESPONDENCE: Sandra Makarović, KBC Osijek, J. Huttlera 4, HR-31000 0sijek, Croatia. / Phone: +385-91-591-68-75 / E-mail: smakarovic36@gmail.com

ORCID: Sandra Makarović, https://orcid.org/0000-0002-7487-1189 • Marin Vučković, https://orcid.org/0000-0003-1010-181X Zorin Makarović, https://orcid.org/0000-0002-6689-3177• Damir Kirner, https://orcid.org/0000-0002-6001-3378

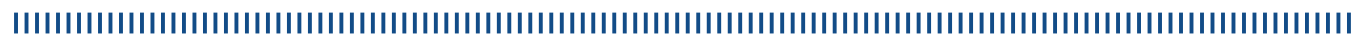

Coronary artery aneurysm is a rare disorder, which occurs in $0.3-4.9 \%$ of patients undergoing coronary angiography and atherosclerosis is the main cause in this disorder in adult population. There are different pathophysiological mechanisms of coronary aneurysm formation and classification. According to the available dana in the literature, the best treatment is unknown. ${ }^{1}$ Case reports in literature, have presented surgical, medical and interventional forms of coronary aneurysms treatment, but the comparison of interventional forms of treatment has not shown the superiority of either method. The question remains regarding the duration of dual antithrombotic therapy.

In our case reports, we show two patients who are resolved by different interventional tools, precisely because of anatomical formation of the aneurysm. Both patients were admitted for acute coronary syndrome, and diagnostic coronary angiography revealed that these were complex lesions that contained large aneurysms within their body. The right coronary artery in one patient was stented with covered stent, while in another patient the interventional treatment of the ostial circumflex artery was done with open cell design drug-eluting stent. Both patients are clinically monitored, and both are in satisfactory clinical condition

Based on our cases we conclude that the possible solution lies in the anatomical position and size of the coronary aneurysm. 